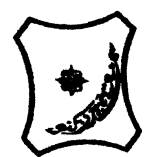

Bayero Journal of Pure and Applied Sciences, 11(1): 8 - 14

Received: January, 2018

Accepted: April, 2018

ISSN $2006-6996$

\title{
GLYCATED HAEMOGLOBIN (HBA1C): AN UPDATE ON AVAILABLE METHODS
}

\author{
Ezegbogu, M.O. ${ }^{1}$ and Abdulsalam, $\mathrm{K}^{2}$
}

${ }^{1}$ Department of Chemical Pathology, University of Benin, Benin, Edo State, Nigeria.

${ }^{2}$ Department of Chemical Pathology and Immunology, Bayero University, Kano/Aminu Kano Teaching Hospital, Kano

Correspondence author: kabdussalam.cpat@buk.edu.ng; +2348039749586

\begin{abstract}
Glycated haemoglobin (HbA1C) assays give a retrospective index of the integrated plasma glucose over an extended period, usually 90-120 days. This period is, however dependent on the average red cell lifespan of the individual. Since its discovery in the $20^{\text {th }}$ century, improvement in the analytical techniques for HbA1c have facilitated its wide acceptance as a useful tool in monitoring glucose control, and more recently, has been recommended for the diagnosis of diabetes mellitus. This review provides an update on the methods available for estimating HbA1c levels in the light of their suitability, advantages, and drawbacks.
\end{abstract}

Keywords: Analytical Methods, Diabetes Mellitus, Glycated Haemoglobin (HbA1c)

\section{INTRODUCTION}

Measurement of glycated proteins, primarily Glycated Haemoglobin is effective in monitoring long-term glucose control in people with diabetes mellitus since It provides a retrospective index of the integrated plasma glucose values over an extended period of time and is not subject to the wide fluctuations observed when assaying blood glucose concentrations (David, 2006). This period of retrospective glucose estimation coincides with the lifespan of healthy red blood cells, which is usually between 90 and 120 days (American Diabetes Care, 2003).

Glycated haemoglobin (HbA1c) has been established as an index of long-term blood glucose concentrations as a measure of the risk of the development of complications in patients with diabetes mellitus (American Diabetes care, 2007). HbA1c assays correlate nicely with mean plasma glucose values (Rohlfing, 2002; Nathan et al., 2008). In addition to being a useful tool for monitoring glucose control in known diabetics, it is now established as a useful tool for screening and diagnosing diabetes mellitus (WHO, 2009). However, misleading HbA1c values may be obtained when the average red cell lifespan is compromised (Xianthis et al., 2007). These conditions include:

1. Increase in red cell turn over, such as blood loss, recent blood donation, haemolysis, haemoglobinopathies (e.g. sickling disease), red cell disorders, myelodysplastic disease, and severe malaria parasitemia (Frank et al., 2000; Roberts et al., 2002; Bain, 2006; Little et al., 2008).

2. Interference with the test; this depends majorly on the test method employed. Common interfering molecules include haemoglobin variants such as $\mathrm{Hb}$ F, S, C, D, and E (Bry and Sacks, 2001; Little and Roberts, 2009).

3. Scenarios where patients' circulating glucose values fluctuate between very high and very low values; in such cases, HbA1c values should be compared with home capillary blood glucose test charts (Gupta et al., 2017).
Historical Perspective of HbA1c

$\mathrm{HbA}_{1 \mathrm{C}}$ was first separated from other forms of haemoglobin by Huisman and Meyering in 1958 using a chromatographic column. It was subsequently characterized as a glycoprotein by Booklin and Gallop in 1968. Its increase in diabetes mellitus was first described in 1969 by Samuel O Rahbar et al. The reactions leading to its formation were characterized by Bunn and his co-workers in 1975 and its use in monitoring the degree of glucose metabolism in diabetic patients was proposed in 1976 by Anthony Cerami, Ronald Koenig, and coworkers. Barely five years on, the HbA1c assay was widely accepted in clinical practice. Consequently, several analytical methods were devised for measuring glycohaemoglobin levels, however, with varying degrees of accuracy and precision. In 2009, an international expert committee appointed by the American Diabetes Association (ADA), International Diabetes Federation (IDF) and the European Association for the Study of Diabetes (EASD) published a report that made the case for using $\mathrm{HbA} 1 \mathrm{C}$ assay to diagnose type 2 diabetes (American Diabetes Association, 2010).

Clinical utility of Glycated Haemoglobin

In the normal approximately 120-day lifespan of the red blood cell, glucose molecules react with haemoglobin, forming glycated haemoglobin. In individuals with poorly controlled diabetes mellitus, the quantities of these glycated haemoglobins are much higher than in healthy people. Once a haemoglobin molecule is glycated, it remains that way throughout its life cycle. Measuring glycated haemoglobin accesses the effectiveness of therapy by monitoring long term serum glucose regulation (International Expert Committee, 2009). The HbA IClevel is proportional to the average blood glucose concentration of four weeks to three months (Nathan et al., 2007). However, it has been suggested that over half of an $\mathrm{HbA1c}$ value is attributable to the previous month, a further quarter to the month before that, and the remaining quarter to the two months before that. 
$\mathrm{HbA}_{\mathrm{IC}}$ is formed by the condensation of glucose with the $\mathrm{N}$-terminal value residue of each $\beta$-chain of $\mathrm{HbA}$ to form an unstable Schiff base (aldimine, pre- $\mathrm{HbA}_{\mathrm{IC}}$ ).
The Schiff base may either dissociate or undergo an Amadori rearrangement to form a stable ketoamine, $\mathrm{HbA}_{1 \mathrm{c}}$ (David, 2006).

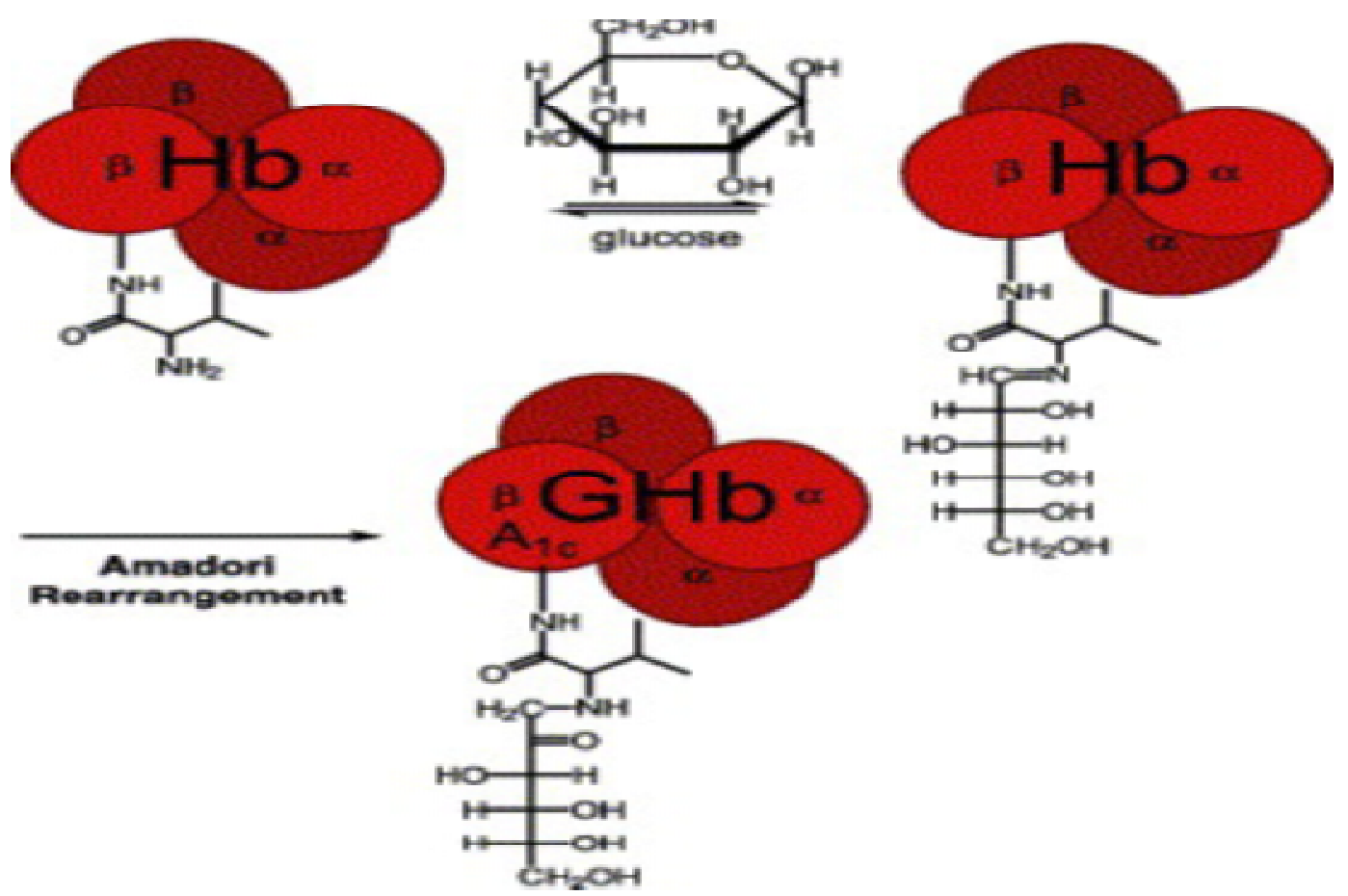

Figure 1: Chemical reaction summarizing the Formation of Glycated Haemoglobin (Burtis CA. et al 2006)

\section{Monitoring and Diagnosis of Diabetes Mellitus}

Numerous studies support the use of $\mathrm{HbA}_{1 \mathrm{c}}$ as an objective measure of glycaemic control (Peacock, 1984; Sacks, 1994; Cagliero et al., 1999; Xanthis et al., 2007; Reynolds et al., 2007; Nathan et al., 2007; Trapp et al., 2008; Gallagher et al., 2009). HbA1c concentrations are therefore a valuable and widely used adjunct to blood glucose determinations for monitoring long-term glycaemic control. In addition, the HbA1c assay is a measure of the risk for the development of complications of diabetes (Sacks et al., 2012). These risks are associated with the likelihood of the development of Advanced Glycation End-products as is commonly seen in diabetics, eventually leading to the development of micro- and macrovascular diabetic complications such as coronary heart disease (Stratton et al., 2000; Selvin et al., 2007), retinopathy (DCCT, 1995; Miyazaki et al., 2004; Trapp, et al., 2008), nephropathy, and neuropathy (Larsen et al., 2010).

Accurate assessment of glycaemic control using $\mathrm{HbA1c}$ assays has helped eliminate the confusion clinicians face in monitoring their patients as a result of the erratic fluctuations accrued to glucose-based methods. For instance, quite different conclusions may be drawn from blood taken at 9.30am soon after breakfast (When blood glucose might be over $20 \mathrm{mmol} / \mathrm{l}$ ) and at the end of an afternoon clinic (when blood glucose in the same patient may be lower than $3 \mathrm{mmol} / \mathrm{L}$ ). Of course, simply measuring HbA1c cannot by itself realize the standards of good glucose control, but the result can indicate whether or not success has been achieved.

Since the wide acceptance of $\mathrm{HbA1c}$ assays in clinical medicine, researchers have made a case for its application on the diagnosis of diabetes mellitus. In July 2009, an international expert committee (appointed by the American Diabetes Association (ADA), International Diabetes Federation (IDF) and the European Association for the Study of Diabetes (EASD) published a report supporting the use of $\mathrm{HbA} 1 \mathrm{C}$ assay to diagnose type 2 diabetes. Use of $\mathrm{HbA1c}$ to diagnose diabetes has been considered by the expert panels in the past, but the idea was roundly rejected (American Diabetes Association, 1997; American Diabetes Association, 2003). The primary obstacle was a lack of standardization of the assay, but that is no longer the case (Consensus Committee, 2007). In fact, $\mathrm{A} 1 \mathrm{C}$ is better standardized than other measurements of glucose (The International Expert Committee, 2009). Other advantages of $\mathrm{HbA1C}$ include the fact that it is a better indication of overall glycemic exposure over time and that there is substantially less day-to-day variability. 
Bajopas Volume 11 Number 1 June, 2018

From a practical standpoint, $\mathrm{HbA} 1 \mathrm{c}$ is much easier to measure because it does not require fasting or timed samples, and it is currently used to manage diabetes. The attractiveness of a single test to both diagnose and manage diabetes, especially while the test is easy to administer and largely reproducible, suggests that 1. greater reliance on the $\mathrm{A} 1 \mathrm{C}$ assay is inevitable. The WHO Consultation concluded that $\mathrm{HbA1c}$ can be used as a diagnostic test for diabetes, provided that stringent quality assurance tests are in place and assays are standardized to criteria aligned to the 2. international reference values, and there are no conditions present which preclude its accurate measurement. An $\mathrm{HbA} 1 \mathrm{c}$ of $6.5 \%$ is recommended as 3 . the cut point for diagnosing diabetes. A value less than $6.5 \%$ does not exclude diabetes diagnosed using glucose tests. The expert group however refrained from making any formal recommendation on the interpretation of $\mathrm{HbA} 1 \mathrm{c}$ levels below $6.5 \%$ as a result of insufficient scientific data at the time (WHO, 2011). Glycated Haemoglobin in Pregnancy

Pregnancy is associated with many physiological derangements including hyperglycaemia which may tend to gestational diabetes mellitus especially in predisposed patients if left unattended. In view of the undoubted impact of diabetic control on foetal wellbeing, it is especially important to aim for and achieve normoglycaemia during gestation (and indeed before conception). Home blood glucose monitoring has allowed women to stay at home up to the time of delivery, overcoming the need for admission to hospital for several months to check blood sugar which used to be routine practice. In these circumstances, it is reassuring to carry out $\mathrm{HbA1C}$ measurements.

Certainly, $\mathrm{HbA}_{1 \mathrm{c}}$ concentrations during pregnancy show a positive correlation with birth weight which is consistent with established experience that large babies are associated with poorly controlled diabetes. There are changes in glucose tolerance during pregnancy even in non-diabetic women, so that "normal" for $\mathrm{HbA}_{1 \mathrm{c}}$ in pregnancy needs to be established separately (Diabetes care, 2007; Yu et al., 2014; Ye et al., 2016). However, Soumya et al (2015) suggested $5.3 \%$ as the diagnostic cut-off for diabetes mellitus in cyesis.

\section{Laboratory Methods for Glycated Haemoglobin} There are nearly one hundred different methods available for measuring glycated haemoglobin (Sacks, 2011). Commercial assays to measure HbA1c became available in 1978 (Davis et al., 1978; Beccaria et al., 1978), and the test gained popularity during the 1980s. The first mention of glycated hemoglobin by the World Health Organization was in 1985 when the potential value of its measurement in diabetes was indicated (WHO, 1985). Three years on, the American Diabetes Association (ADA) suggested that HbA1cdetermination should be performed at least 3 . semiannually for routine monitoring of patients with diabetes (American Diabetes Association, 1985). The commercialization of $\mathrm{HbA} 1 \mathrm{c}$ assays led to the development of a plethora of methods to measure glycated hemoglobin. The general concept underlying these methods is to separate the glycated from the non-glycated hemoglobin and quantify the amount of each (Sacks, 2012).

Laboratory techniques that have been used to achieve this are based on:

Charge differences:

a. Ion-exchange chromatography

b. High performance liquid chromatography (HPLC)

c. Electrophoresis

d. Isoelectric focusing

Structural differences

a. Affinity chromatography

b. Immunoassay

Chemical analysis: (Now obsolete)

a. Photometry

b. Spectrophotometry (David, 2006).

\section{Ion-Exchange Mini-columns.}

Ion-exchange chromatography

separates

haemoglobin variants on the basis of charge. The cation exchange resin (negatively charged), packed in a disposable minicolumn, has affinity for the positively charged haemoglobin. The patient's sample is haemolyzed and an aliquot of the haemolysate is applied to the column. A buffer is applied and the eluent collected. The ionic strength and $\mathrm{pH}$ of the eluent buffer are selected so that $\mathrm{GHbs}$ are less strongly bound to the negatively charged resin and thus are eluted first. The GHbs - $A_{I a}+A_{I b}+A_{I C}$ expressed collectively as $\mathrm{HbA}$, are measured using a spectrophotometer. A second buffer of different ionic strength can be added to the column to elute the more positively charged main haemoglobin fraction. This is read in the spectrophotometer and $\mathrm{GHb}$ is expressed as a percentage of total Haemoglobin (Burtis et al., 2006). Alternatively, only the HbA, is eluted and a separate dilution of the original haemolysate is made, against which the $\mathrm{HbA}$, is compared. In all ion-exchange column methods, it is important to control the temperature of the reagents in order to obtain accurate and reproducible results (David, 2006).

\section{High Performance Liquid Chromatography (HPLC)}

This method uses an ion exchange or affinity column to separate $\mathrm{HbA1c}$ molecules from other hemoglobin molecules (Hamwi, 1995; Camargo and Gross, 2004). The HbA1c content is measured based on the ratio of $\mathrm{HbA1c}$ peak area to the total hemoglobin peak areas. Assays require $5 \mu l_{\text {of }}$ whole blood and finger stick samples can be collected in a capillary tube for analysis. Anticoagulated blood is diluted with a haemolytic agent containing borate. Samples are incubated at $37^{\circ} \mathrm{C}$ for 30 minutes to remove Schiff base and inserted in the autosamplers. One major advantage of this technique is the rapid turn-around time, which is usually as short as $3-5$ mins (David, 2006).

\section{Electrophoresis}

Agar gel electrophoresis on whole blood haemolysates at $\mathrm{pH} 6.3$ provides good resolution of $\mathrm{HbA}$ and $\mathrm{HbA}_{1}$ (Menard et al., 1980). 
Bajopas Volume 11 Number 1 June, 2018

The gel contains negatively charged moieties that interact with the haemoglobin. After 25-35 minutes, the HbA1c separates on the cathodic side of $\mathrm{HbA}$. Quantification is performed by scanning densitometry at $415 \mathrm{~nm}$. Results generally agree well with those obtained by HPLC or column chromatography, but are less precise (Menard et al., 1980; David, 2006).

David (2006) opined that since HbF migrates to the same region as $\mathrm{HbA}$, it may cause a falsely increased $\mathrm{HbA}$. This position was further butressed by Litttleet al (2009). However, Doelman et al., (1997) working independently surmised that $\mathrm{HbA1C}$ assays using capllary electrophoresis is free from interference by haemoglobin variants ( $\mathrm{HbF}, \mathrm{HbC}$, and $\mathrm{HbS}$ ).

\section{Isoelectric Focusing}

The haemoglobin variants separate on isoelectric focusing on the basis of their migration in a gel containing a pH gradient (Spicer et al 1978; Cossuet al., 1984). Ampholines on $\mathrm{pH}$ range of 6-8 establish the gradient in $1 \mathrm{~mm}$-thick acrylamide gel slabs. On completion of isoelectric focusing, the gels are fixed and then scanned on a high-resolution integrating microdensitometer. $\mathrm{HbA}_{\mathrm{ic}}$ is adequately resolved from $\mathrm{HbA}_{\mathrm{Ia}}, \mathrm{HbA}_{\mathrm{IC}}, \mathrm{Hbs}$, and $\mathrm{HbF}$ (Kovalet al., 2011).

\section{Affinity Chromatography}

Affinity gel columns are used to separate $\mathrm{GHb}$, which binds to the column, from the non-glycated fraction. $\mathrm{m}$-aminophenylboronic acid is immobilized by crosslinking to beaded agarose or another matrix (e.g. glass fiber). The boronic acid reacts with the cis-diol groups of glucose bound to haemoglobin to form a reversible five-member ring complex, thus selectively holding the $\mathrm{GHb}$ on the column. The non-glycated haemoglobin does not bind, and Sorbitol is used to elute the GHb. Absorbance of the bound and nonbound fractions, measured at $415 \mathrm{~nm}$, is used to calculate the percentage of $\mathrm{GHb}$

\section{Immunoassay}

Assays of $\mathrm{HbA}_{\mathrm{IC}}$ have been developed using antibodies raised against the Amadori product of glucose (Ketoamine linkage) plus the first few amino acids at the $\mathrm{N}$-terminal and of the $\beta$-cahin of haemoglobin (Engback et al., 1989). The latex enhanced immunoassay method is based on the interactions between antigen molecules (HbA1c) and HbA1c specific antibodies coated onto Latex beads. The agglutinator, a synthetic polymer containing multiple copies of the immunoreactive portion of $\mathrm{HbA}_{\mathrm{IC}}$ blocks the anti- $\mathrm{HbA}_{\mathrm{IC}}$ monoclonal antibody that is attached to latex beads. This agglutination produces light scattering, measured as an increase in absorbance. $\mathrm{HbA}_{1 \mathrm{c}}$ in the patient's sample competes for the antibody on the latex, inhibiting agglutination, thereby decreasing light scattering (Jaisson, et al., 2014; Maurice, 2015). The antibodies do not recognize labile intermediates or other Glycated Haemoglobins (such as $\mathrm{HbA}_{1 \mathrm{a}}, \mathrm{HbA}_{1 \mathrm{~b}}$ ) because both the ketoamine with glucose and the specific amino acid sequences are required for binding. Similarly, other haemoglobin variants, such as $\mathrm{HbF}, \mathrm{HbA}_{2}, \mathrm{HbS}$ and carbomylated haemoglobin are not detected (Bry et al., 2001).

Recent innovation has yielded a Direct Enzymatic HbA1c Assay which uses a single channel test and reports \%HbA1c values directly, without the need for a separate Total Haemoglobin test or a calculation step (Liu et al., 2008). The Direct Enzymatic HbA1c Assay $^{\mathrm{TM}}$ procedure is simple and straight forward. In addition, the reagents do not contain latex particles, and hence do not coat analyzer cuvettes and lines. Most importantly, enzymatic HbA1c assays have the highest specificity among all HbA1c assays with a linearity range from 4 to $16 \%$ (Gupta et al., 2017).

Table 1: A comparison of commonly used methods for estimating HbA1c (Chandalia and Krishnaswamy, (2002)

\begin{tabular}{lcccc}
\hline Analytical Method & $\begin{array}{c}\text { Ion-Exchange } \\
\text { Chromatography }\end{array}$ & HPLC & Immunoassay & $\begin{array}{c}\text { Chemical } \\
\text { Method }\end{array}$ \\
\hline Species measured & HbA1C & HbA1C & HbA1C & Total GHb \\
Pre-HbA1C & YES & $\begin{array}{c}\text { YES (removed } \\
\text { in some) }\end{array}$ & NO & NO \\
$\begin{array}{l}\text { interference } \\
\text { Inter-assay CV }\end{array}$ & YES & YES & NO & NO \\
& $2-10$ & 2 & $6-8$ & $6-8$ \\
\hline
\end{tabular}




\begin{tabular}{|c|c|c|}
\hline Advantages & $\begin{array}{c}\text { Method of } \\
\text { Testing }\end{array}$ & Disadvantages \\
\hline $\begin{array}{l}\text { Reduces the scattering of light } \\
\text { and the absorbance(Maurice, } \\
\text { 2015). } \\
\text { a. Enzymatic assay proved } \\
\text { to be a robust and reliable } \\
\text { method for HbA1c measure } \\
\text { element suitable for routi } \\
\text { ne practice in clinical chemistry } \\
\text { laboratories (Jaissonet al., 2014). } \\
\text { b. The assay is designed to } \\
\text { report \%HbA1c values } \\
\text { directly without need for } \\
\text { a separate measurement } \\
\text { of total hemoglobin and is } \\
\text { not adversely affected by } \\
\text { interferences from com } \\
\text { mon hemoglobin variants } \\
\text { in samples (Liu et al., 2008). }\end{array}$ & $\begin{array}{l}\text { Chromatography } \\
\text { based HPLC } \\
\text { assay }\end{array}$ & $\begin{array}{l}\text { a. Altering the normal process of } \\
\text { gly } \\
\text { cation of HbA to A1C. } \\
\text { b. Causing an abnormal peak on } \\
\text { chromatography, making estima } \\
\text { tion of A1C unreliable. } \\
\text { c. Making the red blood cell more } \\
\text { prone to hemolysis, thereby de } \\
\text { creasing the time for glycosylation } \\
\text { to occur and producing a falsely } \\
\text { low A1C result (Carmago and } \\
\text { Gross, 2004). } \\
\text { a. Time required to complete the } \\
\text { analysis. } \\
\text { b. Technical skills required for han } \\
\text { dling. } \\
\text { c. High price of reagents. }\end{array}$ \\
\hline
\end{tabular}

\section{Standardization of HbA1c Assays}

One of the major drawbacks of the clinical use HbA1c was its lack of Standardization as different test methods reported their values using different formats. This not only confused clinicians, but diabetics as well using $\mathrm{mmol} / \mathrm{L}$ or $\mathrm{mg} / \mathrm{dl}$ for self-monitoring of their day-to-day glucose control found it difficult to understand when their results were discussed in terms of percentages (Hoelzel et al., 2004; Little et al., 2001). In 2007, the International Federation of Clinical Chemistry (IFCC) recommended that $\mathrm{HbA}_{1 \mathrm{c}}$ results be expressed as $\mathrm{mmolHbA}_{1 \mathrm{~d}} / \mathrm{mmolHb}$ instead of $\mathrm{HbA}_{1 \mathrm{c}}$ percentage (Diabetes care, 2007).

To eliminate confusion and streamline these discrepancies, a consensus statement on the worldwide standardization of haemoglobin $A_{1 c}$ measurement was adopted in May 2007 by the American Diabetes Association (ADA), European Association For The Study Of Diabetes (EASD), International Diabetic Federation (IDF) And The International Federation Of Clinical Chemistry (IFCC). It states that new IFCC reference system is the only valid anchor for implementing the standardization of the measurement of $\mathrm{HbA}_{1 \mathrm{c}}$. In addition, $\mathrm{HbA}_{1 \mathrm{c}}$ results were to be reported worldwide in IFCC units (mmolglycatedHb/mol total $\mathrm{Hb}$ ) and derived NGSP units (\%). Using the IFCC-NGSP master equation, the 25 - $42(\mathrm{mmol} / \mathrm{mol})$ range would indicate nondiabetics as the similarly derived NGSP units of the non-diabetic range were $2.5-4.2 \%\left(\mathrm{HbA}_{1 \mathrm{c}}\right)$ (Diabetes Care, 2007).

Table 3: Relationship between the HbA1C units

\begin{tabular}{|c|c|}
\hline Current HbA1c (\%) & New HbA1c (mMol/Mol) \\
\hline 6.0 & 42 \\
\hline 6.5 & 48 \\
\hline 7.0 & 53 \\
\hline 7.5 & 59 \\
\hline 8.0 & 64 \\
\hline 9.0 & 75 \\
\hline
\end{tabular}

IFCC-HbA1c $(\mathrm{mmol} / \mathrm{mol})=[$ DCCT-HbA1c (\%)-2.15] x 10.929 (Gallagher et al., 2009) 


\section{CONCLUSION}

Diabetes mellitus, a metabolic disease characterized by the inability of an individual to properly handle glucose load is a major disease burden worldwide, especially in low and middle-income countries and is predicted to increase from 240 million to 380 million by 2025 (Shaw et al., 2010). Experts have recommended that early diagnosis and effective monitoring of diabetics will significantly improve treatment outcomes. Since the introduction of Glycated Haemoglobin in clinical medicine in the $20^{\text {th }}$ century, it has roundly been accepted as an indispensable tool in monitoring diabetics, and more

\section{REFERENCES}

American Diabetes Association (1989). Standards of medical care for patients with diabetes mellitus. Diabetes Care; 12: 365-368

American Diabetes Association (1997). Report of the expert on the diagnosis and classification of diabetes mellitus. Diabetes Care; 20:S1-S12.

American Diabetes Association (2003). Report of the Expert Committee in the Diagnosis and Classification of Diabetes Mellitus. Diabetes Care;26: S5-S20.

American Diabetes Association (2003). Standards of medical care for patients with diabetes mellitus. Diabetes care; 26 (1): $33-50$.

American Diabetes Association (2007). Standards of Medical care in diabetes. Diab. care. 30 (1): 4 41.

American Diabetes Association (2010). Diagnosis and classification of diabetes mellitus. Diabetes Care; 33:S62-S69.

Bain BJ. Haemoglobinopathy diagnosis. Malden, MA: Blackwell Publishing, Inc.; 2006. p. 210.

Beccaria L, Chiumello G, Gianazza E, Luppis B, Righetti PG (1978). Hemoglobin A1C separation by isoelectric focusing. American Journal of Haematology; 4:367-374.

Bry L, Chen PC, Sacks DB (2001). Effects of hemoglobin variants and chemically modifed derivatives on assays for glycohemoglobin. Clinical Chemistry; 47(2):153 - 163.

Cagliero E, Levina EV, Nathan DM (1999.) Immediate feedback of HbA1c levels improves glycemic control in type 1 and insulin-treated type 2 diabetic patients. Diabetes Care; 22 (11): 17851789.

Camargo JL, Gross JL (2004). Conditions associated with very low values of glycohaemoglobin measured by an HPLC method. Journal of Clinical Pathology; 57(9): 346-349.

Consensus Committee (2007). Consensus statement on the worldwide standardization of the hemoglobin A1C measurement: The American Diabetes Association, European Association for the Study of Diabetes, International Federation of Clinical Chemistry and Laboratory Medicine, and International Diabetes Federation. Diabetes Care; 30:2399-2400.

Cossu G, Manca M, Pirastru MG, Bullita R, Bianchi Bosisio A, Righetti PG. (1984). Determination of glycosylated haemoglobin by isoelectric recently, has been included into the protocol for diagnosis diabetes mellitus (American Diabetes Association, 2010).

This review is aimed at providing an update on the laboratory methods available for $\mathrm{HbA} 1 \mathrm{c}$ estimation as well as their merits and drawbacks. HbA1c assays are commonly executed using Capillary electrophoresis, HPLC, and Immunoassay, although all have their inherent limitations. The immunoassay technique has greater prospects for routine use due to its relatively low cost, rapidity, sensitivity, and specificity. Moreover, it is easy to use and has been adapted as a reliable Point of Care testing Device.

focusing in non-linear $\mathrm{pH}$ gradients. Journal of Chromatography, 307(1):103-110.

David, B.S (2006) in Burtis, C.A., Ashwood, E.R., and Brins, D.E.(Eds). Teitz textbook of clinical chemistry and molecular diagnostics, $4^{\text {th }}$ Ed. New Delhi. Saunders: P. 2412.

Davis JE, McDonald JM, Jarett L. A (1978). Highperformance liquid chromatography method for hemoglobin A1c. Diabetes, 27:102-107.

Diabetes Control and Complications Trial (1995). The relationship of glycemic exposure (HbA1c) to the risk of development and progression of retinopathy in the Diabetes Control and Complications Trial. Diabetes, 44:968-983.

Doelman CJ, Siebelder CW, Nijhof WA, Weykamp CW, Janssens J, Penders TJ. (1997). Capillary electrophoresis system for hemoglobin A1C determinations evaluated. Clinical Chemistry; 43(4):644-648.

Frank EL, Moulton L, Little RR, Wiedmeyer HM, Rohlfng C, Roberts WL. (2000). Effects of hemoglobin C and $\mathrm{S}$ traits on seven glycohemoglobin methods. Clinical Chemistry, 46(6):864-867.

Gallagher EJ, Bloomgarden ZT, Le Roith D. (2009). Review of hemoglobin A1c in the management of diabetes. Journal of Diabetes; 1:9-17.

Gupta, S., Jian, U., and Chauhan, N. (2017). Laboratory Diagnosis of HbA1c: A Review. Journal of Nanomedicine Research; 5(4): 3 - 10.

Hamwi, A., Schweiger, C.R., Veitl M., and Schmid, R. (1995). Quantitative measurement of HbA1c by an immunoturbidimetric assay compared to a standard HPLC method. American Journal of Clinical Pathology; 104(1): 89-95.

Hoelzel W, Weykamp C, and Jeppsson JO (2004). IFCC reference system for measurement of hemoglobin A1C in human blood and the national standardization schemes in the United States, Japan, and Sweden: a methodcomparison study. Clinical Chemistry; 50:166174.

Huismann, T.H., Martis, E. A. and Dozy, A. (1958): Chromatography of haemoglobin types in carboxymethyl cellulose. Journal of Laboratory and Clinical Medicine; 52(2): 312 - 317.

International Expert Committee report on the role of the $\mathrm{A} 1 \mathrm{C}$ assay in the diagnosis of diabetes (2009). Diabetes Care; 32:1327-1334.

Jaisson S, Desmons A, Renard B, Chevelle B, and Leroy N. (2014). Analytical performances of a new enzymatic assay for hemoglobin A1c. ClinicaChemicaActa; 434(1): 48-52. 
Bajopas Volume 11 Number 1 June, 2018

Koenig, R.J. Peterson, C. M., Jones, R.L., Saudek, C., Lehrman, M. and Cerami, A. (1976): Correlation of glucose regulation and haemoglobin $A_{1 c}$ in diabetes mellitus. New England Journal of Medcine; 298 (8): 417 - 420.

Koval, D., Kašičk, V., and Cottet, H. (2011). Analysis of glycated hemoglobin A1C by capillary electrophoresis and capillary isoelectric focusing. Analytical Biochemistry;413: (1) 8-15.

Larsen ML, Horder M.(2010). Effect of long-term monitoring of glycosylated hemogolobin levels in insulin-dependent diabetes mellitus. New England Journal of Medicine; 323 (15); 102115.

Little R.R., Rohlfng C.R., Hanson S., Connolly S., Higgins T. Weykamp C, D'Costa M, Luzzi V, Owen WE, Roberts WL. (2008). Effects of hemoglobin E and $D$ traits on glycated hemoglobin (HbA1c) measurements by twenty-three methods. Clinical Chemistry, 54:1277-82.

Little, R.R., and Roberts, W.L. (2009). A review of variant Haemoglobins interfering with Haemoglobin A1c Measurement. Journal of Diabetes Science and Technology: 3(3): 446 - 451.

Liu L, Hood S, Wang Y, Bezverkov R, and Dou C. (2008) Direct enzymatic assay for \%HbA1c in human whole blood samples. Clinical Biochemistry; 41(7-8): 576-583.

Maurice, O. (2015). The glucose vs. HbA1c controversy. Canterbury Scientific, New Zealand.

Menard, L., Dempsey, M.E., Blackstein, L.A., Aleyassine, H., Wacks, M and Soaldner, J.S. (1980): Quantitative determination of glycosylated haemoglobin $A_{1}$ by agar gel electrophoresis. Clinical Chemistry; 26: $1598-1602$.

Miyazaki M, Kubo M, Kiyohara Y (2004). Comparison of diagnostic methods for diabetes mellitus based on the prevalence of retinopathy in a Japanese population: theHisayama Study. Diabetologia; 47:1411-1415.

Nathan DM, Davidson NB, DeFronco RA, et al. (2007). Impaired glucose and impaired glucose tolerance: Implications for care. Diabetes Care; 30:753-759.

Nathan DM, Turgeon H, Regan S. (2007). Relationship between glycated haemoglobin levels and mean glucose levels over time. Diabetologia; 50:2239-2244.

Nathan, D.M., Kuenen, J., Borg, R., Zheng, H., and Schoenfeld, D. (2008). Translating the A1C assay into estimated average glucose values. Diabetes Care; 31(8): 1473-1478.

O` Rahbar, S., Blumenfeld, O. and Ranney, H. M. (1967): Studies of unusual haemoglobin in patients with diabetes mellitus. Biochemical and Biophysical Research Communications; 36: 838 - 843.

Peacock I (1984) Glycosylated haemoglobin: measurement and clinical use. Journal of Clinical Pathology; 37 (8): 841-851

Reynolds TM, Smellie WS, Twomey PJ (2006) Glycated haemoglobin (HbA1c) monitoring. British Medical Journal; 333(7568): 586-588.

Roberts WL, De BK, Brown D, Hanbury CM, Hoyer JD, John WG, Lambert TL, Lundell RB,

Rohlfng C, Little RR. (2002). Effects of hemoglobin C and $S$ traits on eight glycohemoglobin methods. Clinical Chemistry, 48(2):383-385.
Rohlfing $\mathrm{CL}$, Wiedmeyer $\mathrm{HM}$, Little RR, England JD, TennillA,. (2002) Defining the relationship between plasma glucose and $\mathrm{HbA}(1 \mathrm{c})$ : analysis of glucose profiles and $\mathrm{HbA}(1 \mathrm{c})$ in the Diabetes Control and Complications Trial. Diabetes Care; 25(2): 275-278.

Sacks D.B. (2011). A1C Versus Glucose Testing: A comparison. Diabetes care; 34: 518-523.

Sacks DB. (1994). Carbohydrates. In Tietz Textbook of Clinical Chemistry. 3rd ed. Burtis C, Ashwood E, Eds. Philadelphia, Saunders. p. 928-1001.

Sacks, D.B. (2012). Measurement of Haemoglobin A1c: A new twist on the path to harmony. Diabetes care,35(12): 2674-2680.

Selvin E, Crainiceanau CM, Brancati FL. (2007). Shortterm variability in measures of glycemia and implications for the classification of diabetes. Archives of Internal Medicine; 167:1545-1551.

Shaw, J.E., Sicree, R.A. and Zimmet, P. Z. (2010). Global estimates of the prevelance of diabetes for 2010 and 2030. Diabetes Research and Clinical Practice; 87: 4- 14.

Soumya S, Rohilla M, Chopra S, Dutta S, Bhansali A, Parthan G, Dutta P. (2015). HbA1c: A Useful Screening Test for Gestational Diabetes Mellitus. Diabetes Technology and Therapeutics;17(12):899-904.

Stratton IM, Adler AI, Neil HA. (2000). Association of glycaemia with macrovascular and microvascular complications of type 2 diabetes (UKPDS 35): prospective observational study. British Medical Journal; 321:405-412.

Szwergold, B.S., Howell, S.K. and Beisswerrger, P. J (2002): Non - enzymatic glycation: a novel hypothesis on the aetiology of diabetic complications. Diabetologia. 1245:143 - 152.

Tapp RJ, Tikellis G, Wong TY (2008). Longitudinal association of glucose metabolism with retinopathy: results from the Australian Diabetes Obesity and Lifestyle (AusDiab) study. Diabetes Care;31:1349-1354.

The International Expert Committee (2009). International Expert Committee Report on the role of the A1C assay in the diagnosis of diabetes. Diabetes Care; 32; 1327-1334.

The International Expert Committee (2009). International Expert Committee Report on the role of the A1C assay in the diagnosis of diabetes. Diabetes Care; 32; 1327-1334.

World Health Organization (1985). Diabetes mellitus. Report of a WHO Study Group. World Health Organ Technical Report Series; 727:1-113.

Xanthis A, Hatzitolios A, Koliakos G, Tatola V (2007). Advanced glycosylation end products and nutrition--a possible relation with diabetic atherosclerosis and how to prevent it. Journal of Food Science; 72(8): R125-R129.

Ye M, Liu Y, Cao X, Yao F, Liu B, Li Y, Wang Z, Xiao H. (2016). The utility of $\mathrm{HbA} 1 \mathrm{c}$ for screening gestational diabetes mellitus and its relationship with adverse pregnancy outcomes. Diabetes Research and Clinical Practice; 114:43-49.

Yu, H., Qi, X., and Wang, X. (2014). Application of glycated hemoglobin in the perinatal period. International Journal of Clinical and Experimental Medicine; 7(12): 4653-4659. 